\title{
XXVII. Contributions to the minute anatomy of animals-No. III
}

\section{George Gulliver F.R.S.}

To cite this article: George Gulliver F.R.S. (1842) XXVII. Contributions to the minute anatomy of animals-No. III, Philosophical Magazine Series 3, 21:137, 168-171, DOI: 10.1080/14786444208621512

To link to this article: http://dx.doi.org/10.1080/14786444208621512

册 Published online: 01 Jun 2009.

Submit your article to this journal

Џll Article views: 2

Q View related articles $₫$ 
as to their distinctness : margaric acid melts at $60^{\circ} \mathrm{C}$, the margarate of the oxide of æthyle at $22^{\circ}$; stearophanic acid, on the other hand, has its melting-point at $68^{\circ} \mathrm{C}$, , and its compound with æther at $32^{\circ}$. But this is more effectually proved by the splendid crystallization of the acid and of its soda salt. When compared with the very numerous preparations of fats and their salts in the collections of the Giessen laboratory, they surpassed all in lustre and beauty, and by the well-defined form of the crystals of the soda salt.

As above stated, the acid occurs in a free state in the grains, but only in small quantity, the greater part consists of the oily acid; it probably varies according to the time the grains have been preserved, as is the case with palmitic acid. On the whole the fatty substances may probably constitute 15 per cent. of the grains, of which about a third would consist of the neutral fat. Wittstock obtained 11.2 per cent. of oily matter by pressing the grains between hot plates.

A portion of the oily mass was subjected to dry distillation, and the products boiled with water, from which on cooling a large quantity of sebacic acid was deposited in beautiful needles with a nacrous lustre, and at the same time another fat acid separated on the surface, which was probably margaric acid. This experiment proved the oily fat and oily acid which occur together with that above described in the fruit of Menispermum Cocculus, to be oleine and oleic acid, since, according to Redtenbacher, these alone afford sebacic acid on dry distillation.

The colouring matter which is peculiar to the shells could not be obtained in a state fit for analysis.

XXVII. Contributions to the Minute Anatomy of Animals. By GeOrge Gulliver, F.R.S., \&c. \&c.-No. III*.

On the Pus-like Globules of the Blood.

IN the Philosophical Magazine for September 1838, (S. 3, vol. xiii., p. 193) I have described the frequent occurrence of globules of pus in the blood of persons affected with various severe inflammatory and suppurative diseases, and have since shown how the pale globules of the blood of healthy mammalia and birds differ from the lymph-globules of the same animals (Gerber's Anatomy, p. 83 and 84; Appendix to the same, p. 19; and Philosophical Magazine for June, 1842). In the present communication the globules first mentioned will be compared with the pale globules now so well known as belonging to healthy blood.

* Communicated by the Author. No. II. will be found in our last Nunber, p. 107 . 
In some of my earlier observations these two varieties of globules were doubtiess confounded; and their similarity is often so close, that it may well be questioned whether there is any essential difference between them in many cases, although it is difficult to avoid attributing to the effects of disease the unusual abundance of pus-like globules in the blood of patients labouring under numerous inflammatory distempers.

But it often happens that the pale globules appearing in diseased blood are manifestly different from those found in the blood during health. The former are generally rather larger, more irregular in size and form, and not uncommonly more opake than the latter. The globules occurring in disease too often appear to be tinged, especially when examined by lamplight, of a red colour, like the blood-corpuscles described by Dr. Barry as in progress of change into pus-globules.

Case 1.-A mare, aged 19, was lame of the hind-leg, which in three days became prodigiously swoln; there were many purulent deposits beneath the integuments, and she had much fever. Some blood, from the facial vein, was now examined, and found to contain an unusual number of pus-like globules, (fig. 1. A.) the average diameter of which was about $\frac{1}{2} \frac{1}{6} \frac{6}{6}$ th of an English inch. They occurred for the most part singly, and occasionally in clumps. When treated with dilute acetic acid the globules exhibited nuclei, generally central but sometimes attached to the circumference; and the smaller particles or molecules (the disc-like objects of Dr. Barry), of which the nuclei were composed were either closely connected together or separated by minutely granular matter (fig. 1. B.). On the fifth day, when the disease had increased, some blood from a cutaneous vein of the affected limb contained about half as many pus-like globules as red discs; the former were most commonly in clusters, and darker-coloured than they were two days before.

The pale globules in the blood of a healthy mare, examined at the same time for comparison, were by no means so numerous; they were more regular in size and shape, almost all between $\frac{1}{3} \frac{1}{50} \overline{0}$ th and $\frac{1}{2} \frac{1}{5} 0$ th of an inch in diameter; when subjected to the action of dilute acetic acid they presented a nucleus, the molecules of which were closely aggregated together; the globules appeared rather paler than those of the diseased blood, and were rarely to be seen in clumps (fig. 1. C.).

Case 2.-A gelding, aged 8, had the disease termed by veteriuarians laminitis, that is to say, inflammation of the vascular laminæ of the corion beneath the crust of the hoof. The disease was violent; relief was attempted by abstracting blood from the brachial vein, which became inflamed, and the animal soon afterwards diecl. In the blood there was a 
vast number of pale globules resembling pus, (fig. 2, A.) besides others of a reddish colour. The latter corpuscles (fig. 2 , B.) appeared to be composed of very delicate pale envelopes including from one to four blood-discs, rarely five or six, some of which were altered in shape, while others presented nearly their usual size and contour. They were not spherical, as some of them appear to be in the figure. The envelopes, which seemed at first like shadows, were distinct enough in different lights, even after the addition of water and dilute acetic acid, and were rendered very obvious by the action of tincture of iodine.

Fig. 1.

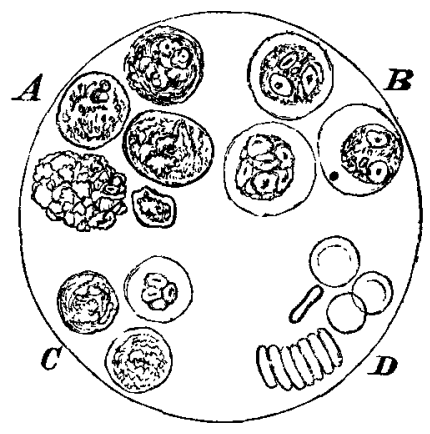

Fig. 2.

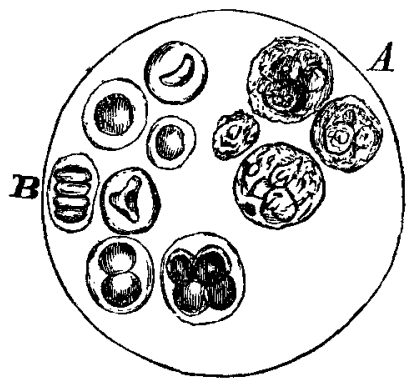

Fig. 1. Globules mentioned in case 1. A, pus-like globules of blood from the facial vein; two of them are round, another is rather oval, a fourth is made up of aggregated granules, and the remaining one is much smaller and more shapeless than the others. B, the same globules treated with dilute acetic acid. C, pale globules from the blood of a healthy mare, in one of which the nucleus is shown by dilute acetic acid. D, blood-discs or unchanged red particles from the same animal for comparison.

Fig. 2. Corpuscles described in case 2. A, pus-like globules of blood from the digital vein, as they appeared without addition. B, reddish corpuscles, of which seven are here depicted, from the same blood ; four of them contain what appear to be single blood-discs, three of which are variously misshapen ; of the three other corpuscles one includes two discs seen on their flat surfaces and touching merely at the margins, another has four slightly overlapping at the edges, and the remaining one incloses a pile of similar discs seen on their edges and with their flat surfaces together. Compare these dises with the unchanged red particles at $D$ in fig. 1 .

All the objects in both figures are magnified exactly to the same degree, namely, about 800 diameters. Compare the nu- 
clei at $\mathrm{B}$ and $\mathrm{C}$ in fig. 1, with those of the lymph and chyle globules, which I have depicted in Gerber's Anatomy.

\section{Structure of Fibrine.}

In the section on this subject in the last Number of the Philosophical Magazine, p. 109-111, it should have been stated that in many fibrinous exudations or false membranes, resulting from inflammation, the structure is the same as that of fibrine, coagulated either after removal from the body or within the circulating channels simply from death. In false membranes the fibrils are often very distinct: they form a delicate net-work, which incloses exudation corpuscles, much resembling the organic germs before described in pale clots of fibrine formed without inflammatory action. As these fibrils in both instances appear to be formed in the act of coagulation, it would require some modification of or departure from the theory of M. Schwann to explain their origin.

\section{Tubercle.}

It has long been a question whether tubercular matter in the lungs be situated in the cellular (filamentous) tissue outside the air-cells, or at the surface of the mucous membrane within these cells. It may be merely mentioned that $I$ have clearly detected tubercular deposit in the latter situation; and that Dr. Willis, in his forthcoming English version of Prof. Wagner's Physiology, will give an engraving of tubercular matter within the air-cells. This of course will not decide what is always the case in tubercular consumption; but it seems to be a fact of interest in regard to the precise seat of tubercle of the lungs.

XXVIII. On the Preparation of Quina and Cinchonia. $B y$ M. F. C. Calvert, Préparateur du Cours de Chimie appliquée au Jardiu des Plantes à Paris.

To the Editors of the Philosophical Magazine and Journal. GENTLEMEN,

A LLOW me, through the medium of your widely-circulated A Journal, to make public a new chemical fact discovered by me relating to the extraction of quina and cinchonia from cinchona bark, by the knowledge of which, I believe, the process usually followed by the manufacturers of these alkaloids may be considerably improved.

In order to obviate some of the difficulties which have hitherto been experienced in extracting the alkaline bases of cinchonia, it appeared to me desirable to discover a process by which, from a certain quantity of cinchona. bark, all the quina and cinchonia contained in it might be extracted. In 